\title{
INOVAÇÃO TECNOLÓGICA APLICADA AOS NEGÓCIOS
}

Congresso Nacional Online de Empreendedorismo, 3ạ edição, de 06/12/2021 a 08/12/2021 ISBN dos Anais: 978-65-81152-30-7

LEAL; Thamires Lemes ${ }^{1}$, CARVAlHO; Matheus Almeida De ${ }^{2}$, MASSENA; Vinicius de Abreu ${ }^{3}$, CASTRO; Tiago Ruiz de ${ }^{4}$, ÁVILA; Wellington 5

\section{RESUMO}

Destaca a importância da tecnologia diariamente nas operações das empresas, principalmente no que tange o atendimento ao cliente e na área de propaganda e marketing. Para essa pesquisa buscou-se tratar dos chatbots, que são robôs programados para executar tarefas mais rapidamente que humanos e que são amplamente usados e tem sido difundido dia após dia. A presente pesquisa, objetiva-se em identificar a necessidade do uso da tecnologia para melhorar o atendimento, aumentar a retenção de clientes visando um lucro maior. Foi realizada uma breve pesquisa em renomados websites e em literatura especializada com 0 intuito de verificar as vantagens do uso de chatbots. Também através dessa pesquisa foi possível identificar o tamanho das empresas que optaram por usar chatbots e outras tecnologias a fim de melhorar o desempenho e resultado da mesma. Foi identificado com base na pesquisa realizada as principais vantagens do uso dos chatbots, especificamente, em uma empresa ou negócio. Entre elas estão a diminuição do custo de recursos humanos para atendimento ao automatizar essas tarefas em caso de problemas específicos e repetitivos que são facilmente programáveis. Também é possível ampliar o horário de atendimento por $24 \mathrm{~h}$, estreitando o relacionamento e aumentando a satisfação do cliente. Possibilidade de criar um amplo banco de dados com informações dos clientes e oferecer um atendimento mais personalizado sabendo a data de aniversário do mesmo e oferecer cupons de desconto e mimos de forma automatizada. Aumento da produtividade, pois não se faz necessário gastar tanto tempo com atendimentos básicos, podendo focar em situações específicas e em planejamento. Existe a possibilidade de integrar chatbots com marketplaces e outras plataformas, aumentando o alcance de anúncios personalizados para determinado público-alvo. Esses prospectos chegam até um atendimento personalizado com captação de dados para contato e futuras prospecções, possibilitando levar um produto personalizado de acordo com a necessidade do cliente, aumentando as chances de vendas e retenção desse cliente. Foi verificado que grandes empresas reconhecidas no mercado já fazem o uso de chatbots diariamente, inclusive em contatos iniciais com o cliente o que possibilita menos espera na fila de atendimento. Conclui-se que o uso da tecnologia vem crescendo nas empresas cada vez mais, os chatbots são adotados diariamente por empresas que desejam profissionalizar seu atendimento, diminuir a espera, automatizar algumas tarefas reduzindo o gasto com contratação de pessoal para atendimento ao cliente. Também se faz necessário a 
contratação de tal serviço por uma empresa sólida, para que o atendimento não tenha falhas e ao invés de agilizar o mesmo possa causar reclamações por parte dos clientes. Para isso é fundamental uma pesquisa das opções mais procuradas durante o atendimento, elaboração de um menu com cada opção bem definida. Ter em mente a quantidade de clientes que podem entrar em contato diariamente e caso aconteça algum problema se a demanda aumentaria e em quanto, para que a central possa suportar. A tecnologia é uma solução importante e válida para empresas porém deve ser bem planejada, elaborada e testada antes de inserir no mercado para o cliente final.

PALAVRAS-CHAVE: Atendimento, Chatbots, Empreendedorismo, Marketing, Tecnologia 